\title{
Revisión: Aspectos fundamentales de la flotación de apatita, calcita, hematita, magnesita y cuarzo usando la bacteria Rhodococcus opacus
}

\author{
Carlos Alberto Castañeda Olivera ${ }^{1,2}$, Jhonatan Gerardo Soto Puelles ${ }^{2}$ \\ ${ }^{1}$ Escuela Profesional de Ingeniería Ambiental, Universidad César Vallejo, Av. Alfredo Mendiola 6232, Los \\ Olivos, Lima, Perú \\ 2 Departamento de Ingeniería Química y de Materiales, Pontificia Universidad Católica de Rio de Janeiro, Rua \\ Marquês de São Vicente, 225 - Gávea - Rio de Janeiro - CEP: 22453-900, Brasil
}

Recibido 3 de agosto. Revisado 8 de diciembre. Aprobado 17 de diciembre 2019.

DOI: https://doi.org/10.33017/RevECIPeru2019.0009/

\section{Resumen}

Este artículo presenta una revisión sobre los estudios de la bacteria Rhodococcus opacus como bioreactivo en la flotación de minerales. La microflotación de apatita, calcita, hematita, magnetita y cuarzo mostró que la bacteria Rhodococcus opacus tiene potencial como un bioreactivo en la flotación mineral. Además, las mediciones electrocinéticas indicaron que la interacción electrostática juega un papel determinante en la adhesión bacteria-mineral. Por otro lado, la espectroscopía infrarroja con transformada de Fourier (FTIR), detectó una cantidad significativa de grupos carboxílicos y amino en la pared celular bacteriana; la disociación de estos grupos puede ser responsable de la carga superficial negativa de las bacterias en un amplio intervalo de $\mathrm{pH}$, así como su punto isoeléctrico (PIE) ácido, alrededor de 2,5. Otros estudios como la teoría XDLVO y el enfoque termodinámico, informaron que las interacciones hidrofóbicas/hidrofílicas, así como las fuerzas de van der Waals también están implicados en los fenómenos de adhesión. Finalmente, las imágenes microscopía electrónica de barrido (MEB) confirmaron la afinidad y selectividad de la bacteria Rhodococcus opacus sobre las superficies minerales.

Descriptores: Flotación, Rhodococcus opacus, bioreactivo, mineral.

\section{Abstract}

This article presents a review on the studies of the Rhodococcus opacus bacteria as bioreagent in mineral flotation. The microflotation of apatite, calcite, hematite, magnesite and quartz showed that the Rhodococcus opacus bacteria has potential as a bioreagent. In addition, electrokinetic measurements indicated that electrostatic interaction plays a decisive role in bacterial-mineral adhesion. On the other hand, On the other hand, Fourier transform infrared spectroscopy (FTIR) detected a significant amount of carboxylic and amino groups in the bacterial cell wall; the dissociation of these groups can be responsible for the negative surface charge of the bacteria over a wide $\mathrm{pH}$ range, as well as their isoelectric point (IEP) acid, around 2.5. Other studies, such as the XDLVO theory and the thermodynamic approach, reported that hydrophobic/hydrophilic interactions as well as van der Waals forces are also involved in adhesion phenomena. Finally, scanning electron microscopy (SEM) images confirmed the affinity and selectivity of the Rhodococcus opacus bacteria on the mineral surfaces.

Keywords: Flotation, Rhodococcus opacus, bioreagent, mineral. 


\section{Introducción}

La bioflotación es el proceso de flotación selectiva de partículas minerales utilizando material biológico como reactivos. Reducen considerablemente el impacto ambiental, en comparación con los reactivos sintéticos, debido a su baja toxicidad y rápida biodegradabilidad. Además, debido a sus diversos grupos funcionales, tienen una notable selectividad, convirtiéndose en una posible solución para el tratamiento de depósitos minerales de baja ley.

Existen varios estudios que tratan la interacción entre diferentes tipos de bacterias y superficies minerales [1]. Se informó que puede existir una fase de adhesión primaria, gobernada por interacciones físicas y/o químicas entre las células planctónicas y la superficie mineral (sustrato), mientras que los procesos biológicos como el crecimiento y la adaptación del fenotipo a las condiciones en el sustrato pueden involucrar escalas de tiempo más grandes [2]. Los biopolímeros presentados en la pared celular del microorganismo pueden ser responsables del enlace entre las partículas minerales y la biomasa [3-5].

\section{Estudios de bioflotación}

\subsection{Estudios electrocinéticos}

[6], estudiaron la bioflotación de hematita y cuarzo utilizando Rhodococcus opacus como reactivo colector. EI PIE para las muestras minerales correspondió a valores de $\mathrm{pH}$ de aproximadamente 2,0 para cuarzo y 5,1 para hematita. De acuerdo con estos resultados, fue posible prever una región potencial para la interacción electrostática entre las muestras minerales y las células de $R$. opacus. Para el cuarzo, se informó que esta región existe a valores de $\mathrm{pH}$ por debajo de 3,5, y para la hematita en el rango de $\mathrm{pH}$ de 3,2 a 5,5. En estas regiones, la carga superficial de la bacteria y partículas minerales es opuesta; entonces existe una fuerza atractiva debido a las interacciones electrostáticas. Después de la interacción con la bacteria, las propiedades de la superficie de ambos minerales cambiaron tal como lo demuestra su perfil de potencial zeta. Además, hubo un desplazamiento en el PIE, que pasó de 5,1 a 2,6 en el caso de la hematita, y de aproximadamente 2,0 a 3,7 en el caso del cuarzo [6]. Cabe señalar que las superficies minerales se vuelven hidrófobas a medida que se acercan a sus PIEs. En el caso del cuarzo, antes de la interacción bacteriana, no fue posible determinar su PIE en el rango de $\mathrm{pH}$ estudiado; sin embargo, después de la interacción bacteriana, la superficie de cuarzo fue modificada y alcanzó un PIE de 3,7. [7] propuso que los cambios en los valores de PIE se debieron a la adsorción específica de los grupos funcionales de $R$. opacus sobre las superficies minerales. [8,9] también observó alteraciones similares en el perfil electrocinético para muestras de calcita, cuarzo, dolomita, corindón y hematita, después de la interacción con células de Bacillus polymyxa. La Figura 1 muestra el potencial zeta de las células de $R$. opacus, el cuarzo y la hematita en función del pH.
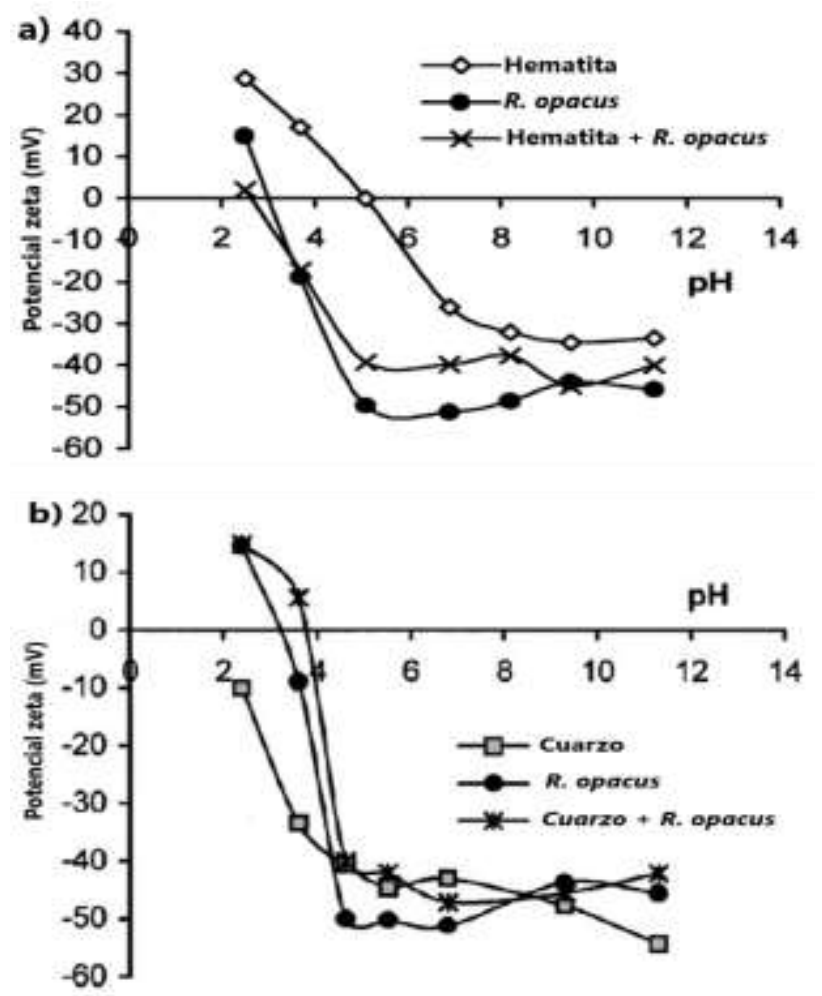

Figura 1: Potencial Zeta de las células R. opacus, cuarzo y hematita en función del $\mathrm{pH}$, utilizando un tamaño medio de partícula de $37 \mu \mathrm{m}, \mathrm{NaCl} 0,1 \mathrm{mM}$ como electrolito indiferente y concentración celular de $600 \mathrm{mg}^{-\mathrm{dm}^{-3}}$. a) Para la hematita antes $y$ después de la interacción con la suspensión celular de R. opacus. b) Para el cuarzo antes y después de la interacción con la suspensión celular de $R$. opacus [6].

[10] estudió la flotación de calcita y magnesita con $R$. opacus. La Figura 2 muestra las curvas de potencial zeta de $R$. opacus, calcita y magnesita en función del $\mathrm{pH}$, antes y después de la interacción. La presencia de polisacáridos, fosfatos y grupos amino en la pared celular confirió una carga neta en la superficie que depende en gran medida del $\mathrm{pH}$ [11]. Los resultados estuvieron de acuerdo 
con [12] y [13], donde los valores de PIE estaban alrededor de 8,2 y 10 para magnesita y calcita, respectivamente. Los cambios en los valores de PIE de la calcita y magnesita después de la interacción con $R$. opacus pueden atribuirse a la secreción de compuestos bacterianos proteicos que interactúan con las superficies minerales [14].

[15], estudiaron la flotación de cuarzo y apatita con $R$. opacus. El cambio en los perfiles de potencial zeta de ambos minerales, después de la interacción con las células de $R$. opacus, puede ser evidencia de la adsorción de las células y/o productos metabólicos sobre las superficies minerales [5,6,14,16-21]. La Figura 3 muestra los resultados de potencial zeta.

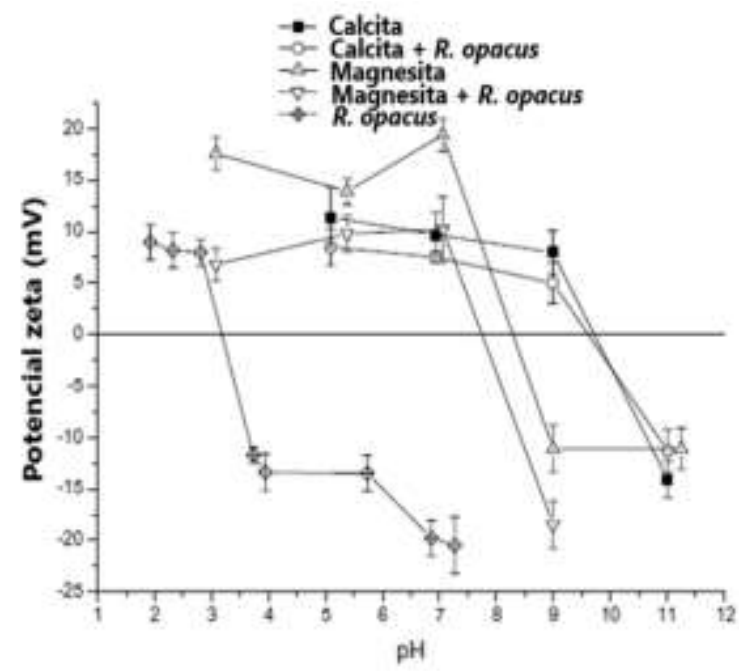

Figura 2: Curvas de potencial de Zeta de R. opacus, calcita y magnesita en función del $\mathrm{pH}$, antes $y$ después de la interacción, utilizando un tamaño medio de partícula de $37 \mu \mathrm{m}, 0,01 \mathrm{M}$ de $\mathrm{NaCl}$ como electrolito indiferente y $100{\mathrm{mg} . \mathrm{dm}^{-3}}^{\text {de }}$ concentración celular [10].

\subsection{Estudios de adhesión}

Con respecto a los estudios de adhesión de hematita y cuarzo, [6] mostraron que la cantidad adherida de microorganismos es significativamente a pH ácido. La mayor adhesión de las bacterias sobre la superficie de hematita en comparación con el cuarzo puede deberse a que la última tiene una carga superficial negativa, por lo que repele las células; estos resultados estuvieron de acuerdo con los estudios de potencial zeta que indican que la interacción electrostática jugó un papel determinante en los fenómenos. La Figura 4 muestra los resultados.

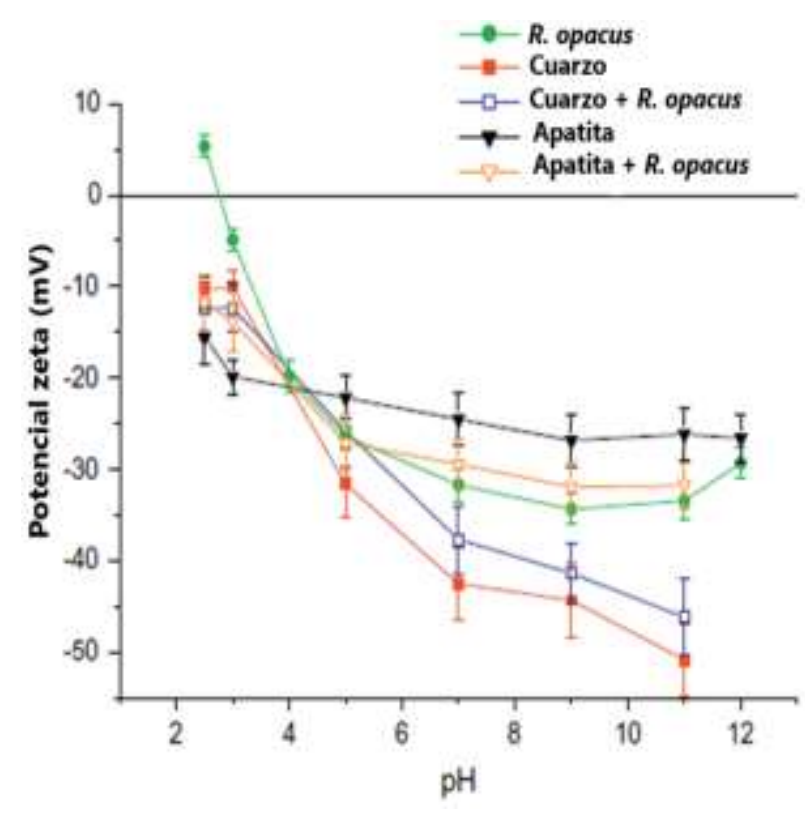

Figura 3: Potencial Zeta de las muestras de cuarzo y apatita, antes y después de la interacción con $R$. opacus, utilizando un tamaño de partícula $<20 \mu \mathrm{m}$, $\mathrm{NaCl} 10^{-3} \mathrm{M}$ como electrolito indiferente $y$ concentración bacteriana, 0,10 g.dm-1 [15].

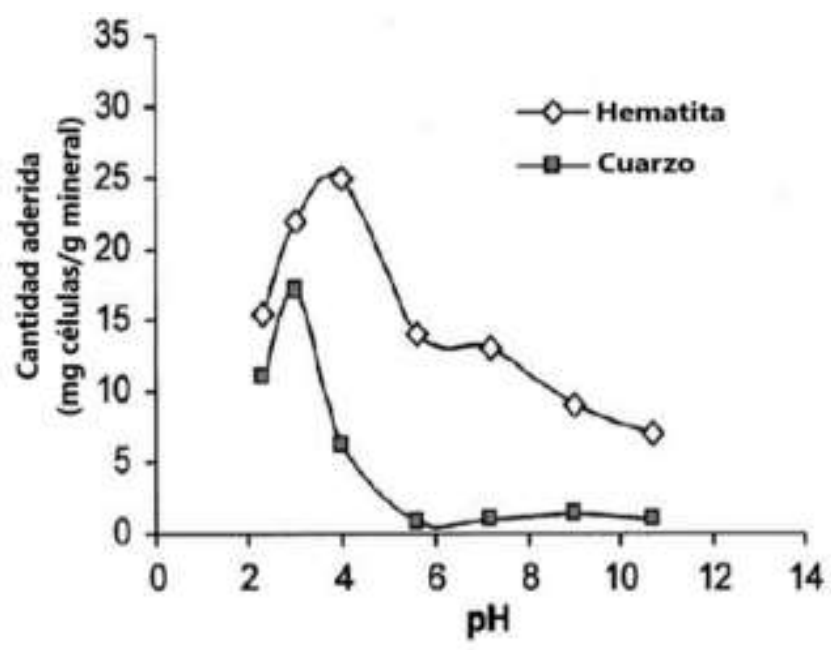

Figura 4: Adhesión de las células R. opacus sobre la superficie de hematita y cuarzo en función del $\mathrm{pH}$, utilizando $1,5 \mathrm{~g}$ de muestra mineral $(<37 \mu \mathrm{m}), 80 \mathrm{ml}$ de concentración celular, 0,1 $\mathrm{mM}$ de $\mathrm{NaCl}$ como electrolítico indiferente y concentración celular de $600 \mathrm{mg} \cdot \mathrm{dm}^{-3}$.

En el caso de los estudios de adhesión de la calcita y magnesita. Los resultados indicaron una mayor afinidad de las bacterias por la magnesita que la calcita [10], Fig. 5. La calcita se estudió a valores de $\mathrm{pH}$ superiores a 5 , debido a su solubilidad a valores menores. Los estudios electrocinéticos de 
magnesita predijeron un aumento de la adhesión bacteriana hasta un $\mathrm{pH}$ de 8.5 , disminuyendo a valores de $\mathrm{pH}$ mayores, lo que podría explicarse por la repulsión electrostática entre las células y el mineral. Los estudios de potencial Zeta de calcita no fueron de acuerdo con los resultados de adhesión, indicando la presencia de otro tipo de interacciones que se superan aparte de la atracción/repulsión electrostática.

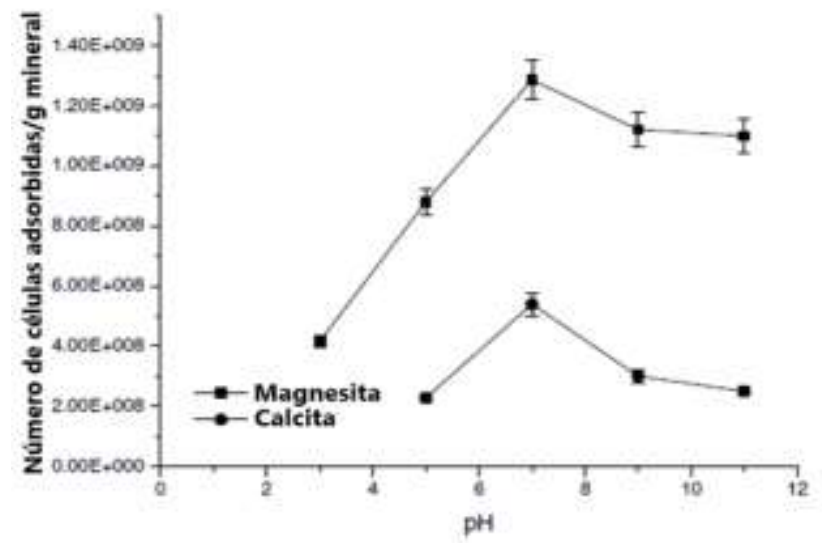

Figura 5: Experimentos de adhesión de R. opacus en calcita y magnesita en función del $\mathrm{pH}$, utilizando un tamaño medio de partícula de $74 \mu \mathrm{m}, 0,01 \mathrm{M}$ de $\mathrm{NaCl}$ como electrolito indiferente y $0.5 \mathrm{~g} . \mathrm{dm}^{-3}$ de concentración celular [10].

\subsection{Test de microflotación}

[6] informaron que la flotación de hematita con $R$. opacus tuvo una recuperación significativa, alrededor del $90 \%$, a pH 4. Por otro lado, la flotabilidad del cuarzo fue considerablemente menor en comparación con la recuperación de hematita, Fig. 6. Estos resultados fueron de acuerdo con los estudios de potencial zeta y estudios de adhesión. Para la hematita, además de las interacciones electrostáticas, puede haber adsorción química que explicaría la mayor afinidad y selectividad de la biomasa [22].

Además, [10] estudió la flotación de magnesita y calcita. La magnesita alcanzó una flotación óptima del $92 \%$, utilizando 100 ppm de $R$. opacus a pH 5 y los mejores resultados de flotabilidad para la calcita fueron de alrededor del $55 \%$ para una concentración de $R$. opacus de 220 ppm a pH de alrededor de 7 (Fig. 7). La recuperación de magnesita disminuyó cuando la suspensión celular se incrementó hasta 200 ppm; esto podría explicarse por la formación de hemimicelas que conducen a una inversión de carga $y$, en consecuencia, disminuyen la cantidad de mineral flotado.
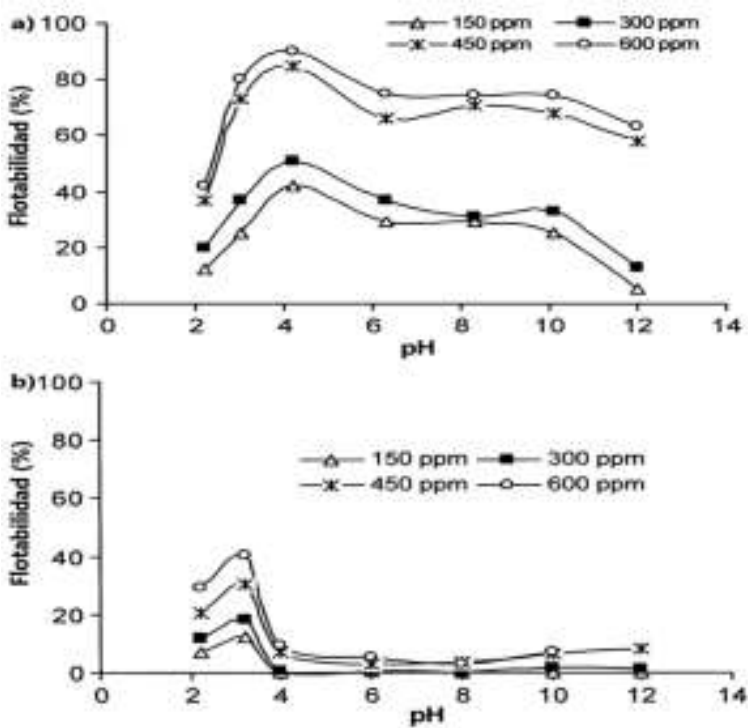

Figura 6: Test de flotabilidad para $1 \mathrm{~g}$ de mineral

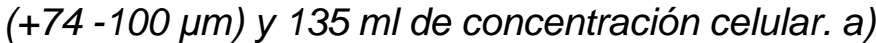
Flotabilidad de la hematita. b) Flotabilidad del cuarzo [6].
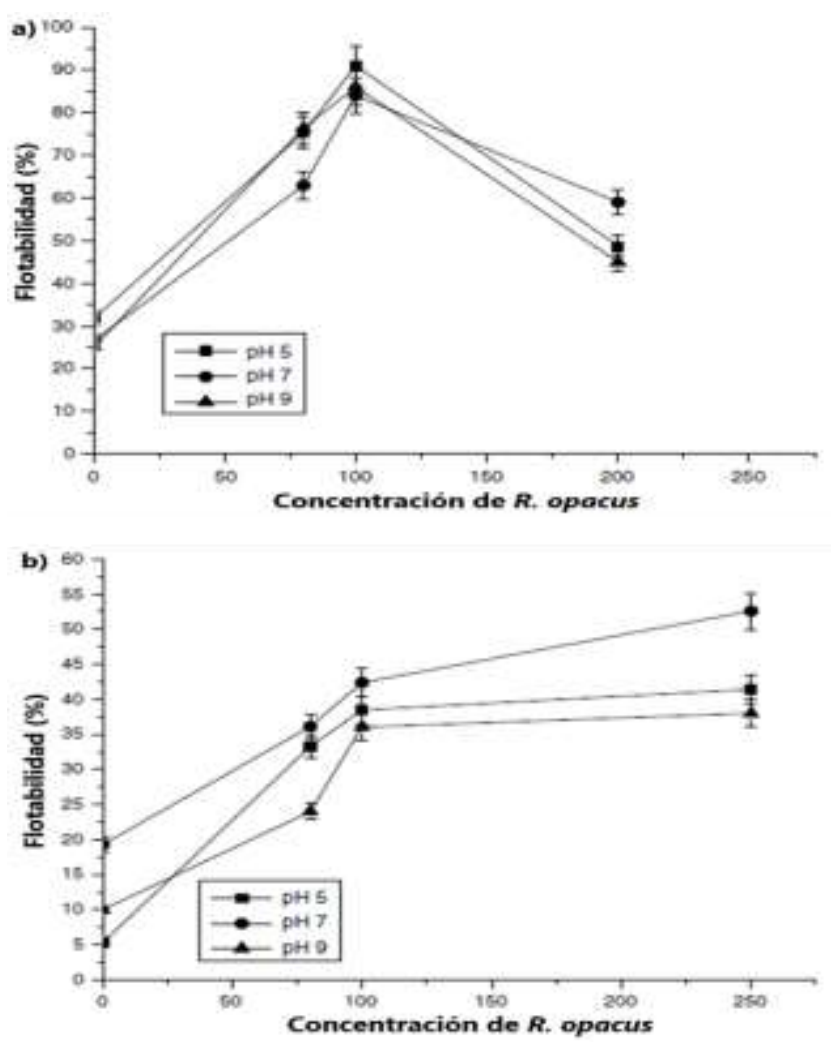

Figura 7: Flotabilidad de magnesita (a) y calcita (b) en función de la concentración de $R$. opacus a diferentes valores de $\mathrm{pH}$, utilizando un tamaño medio de partícula de $106 \mu \mathrm{m}, 0,8 \mathrm{~g}$ de mineral y $0,17 \mathrm{dm}^{-3}$ de suspensión celular [10]. 
[15] estudió la flotabilidad de apatita y cuarzo. La Fig. 8 muestra la flotabilidad de apatita y cuarzo en función de la concentración celular y el pH; en estas condiciones, la flotabilidad máxima de apatita y cuarzo fue de $60 \%$ y $14 \%$, respectivamente, después de 2 minutos de flotación. La flotabilidad óptima para apatita y cuarzo se alcanzó a pH 5, sin embargo, según las mediciones de potencial zeta (Fig. 3), las bacterias y la superficie mineral pueden tener una carga eléctrica similar; por lo tanto, pueden existir otros mecanismos que podrían superar la interacción electrostática. [23], sugirió un mecanismo indirecto en el que los metabolitos de la bacteria funcionaban como reactivos activos.
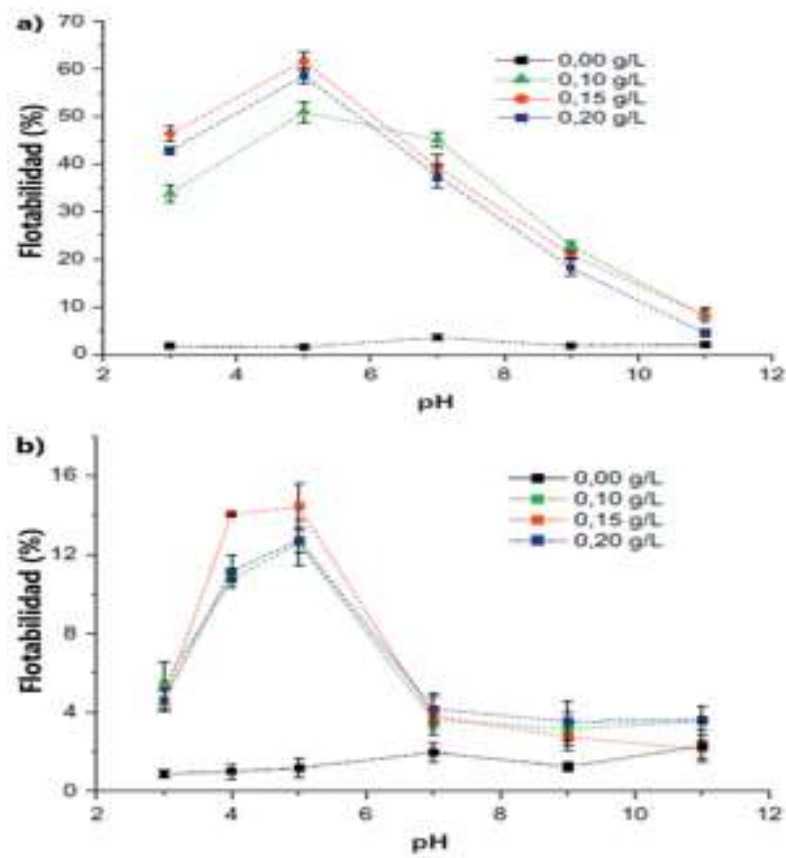

Figura 8: Microflotation de apatita (a) y cuarzo (b) en función de la concentración celular y el pH, utilizando un tamaño de partícula de +75-106 $\mu \mathrm{m}$, un tiempo de flotación de $2 \mathrm{~min}$, $1 \mathrm{~g}$ de mineral y $0,16 \mathrm{dm}^{-3}$ de suspensión celular [15].

[26] estudió el proceso de electroflotación de partículas finas de hematita. La mejor flotabilidad de hematita con $R$. opacus fue alcanzada en las condiciones de $\mathrm{pH} 6$, densidad de corriente de $22,18 \mathrm{~mA} / \mathrm{cm}^{2}$, un tamaño de partícula de $-20 \mu \mathrm{m}$ y una concentración de bioreactivo de $300 \mathrm{mg} / \mathrm{L}$. La recuperación de hematita fue alrededor del $80 \%$ con burbujas de hidrógeno y alrededor del $70 \%$ con burbujas de oxígeno.

\subsection{Enfoque DLVO y X-DLVO}

Basado en la teoría clásica de DLVO, [6] evaluó la interacción entre las partículas de hematita, cuarzo y las células de $R$. opacus. Para ambos sistemas, cuarzo-células y hematita-células, no hubo presencia de un mínimo de interacción secundaria, lo que sugiere una adhesión fácilmente revertida [24]. En el caso del sistema hematitacélulas (Fig. 9), la teoría DLVO mostró atracción entre las células de $R$. opacus y las partículas minerales en el rango de $\mathrm{pH}$ de 3,5 a 5,5. Esto estaba de acuerdo con las mediciones de potencial zeta, que indicaban que la hematita y las células de $R$. opacus tenían cargas superficiales opuestas. Sin embargo, los experimentos de adhesión de hematita a diferentes valores de pH (Fig. 4), también demostraron que existe afinidad con otros valores de $\mathrm{pH}$. Aunque esta afinidad es menor en comparación con el rango de pH de la interacción electrostática, sigue siendo significativa; así, las células de $R$. opacus superaron la barrera energética que impide la adhesión a la superficie de hematita por otro mecanismo diferente de la interacción electrostática y las fuerzas de van der Waals. Los resultados indicaron un mecanismo indirecto, debido a reactivos biológicos como los metabolitos secretados y EPS (sustancias poliméricas extracelulares) que actúan como reactivos tensioactivos [23] o a fracciones solubles de los microorganismos derivados de su ruptura celular $[18,25]$.

Para las células de $R$. opacus y las partículas de cuarzo, los resultados obtenidos con los experimentos de adhesión, ángulo de contacto y microflotación fueron de acuerdo con la teoría DLVO, donde había afinidad en el rango de $\mathrm{pH} 2,2$ y 3,5 (Fig.10).

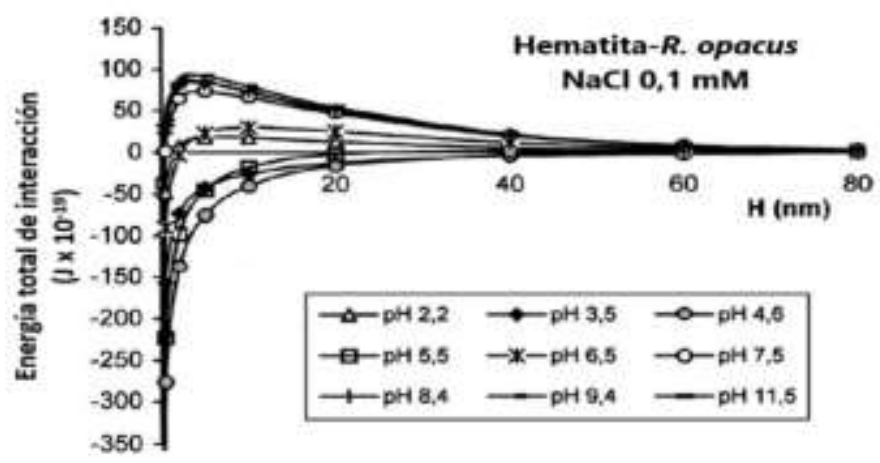

Figura 9: Energía de interacción total entre partículas de hematita y células de $R$. opacus en función de la distancia a diferentes valores de $\mathrm{pH}[6]$. 


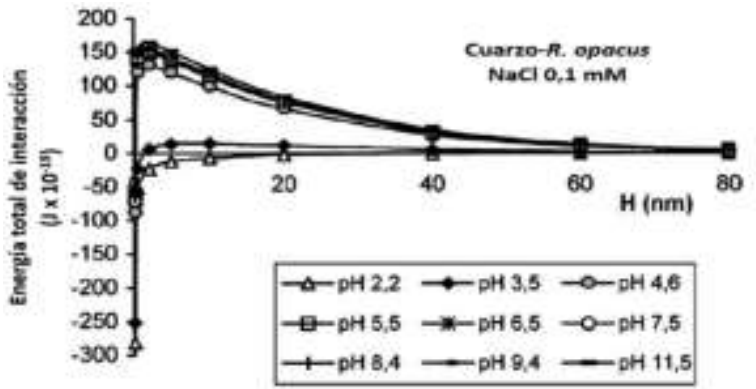

Figura 10: Energía de interacción total entre partículas de cuarzo y células de $R$. opacus en función de la distancia a diferentes valores de $\mathrm{pH}[6]$.

[14] estimaron las componentes interfacial para $R$. opacus, calcita y magnesita, así como la energía de interacción, $\Delta \mathrm{G}^{\text {adh }}$, para los sistemas de bacteriamineral. La Tabla 5 muestra los resultados, donde $\mathrm{Y}^{+} \mathrm{y}^{\mathrm{V}}$ son parámetros de aceptor de electrones y donador de electrones, respectivamente, $\mathrm{Y}^{\mathrm{LW}}$ representa el componente de tensión superficial Lifshitz-van der Waals, $\Delta \mathrm{G}^{\mathrm{LW}}$ es la energía de interacción debida a las fuerzas de Lifshitz-van der Waals y $\Delta G^{A B}$ es la energía de interacción ácidobase, que explica las interacciones hidrófilashidrófobas. $\Delta \mathrm{G}^{\text {adh }}$ para la calcita fue mayor que para la magnesita, por lo que la adhesión de $R$. opacus sobre la superficie de magnesita fue más energéticamente favorable; que estaba de acuerdo con las pruebas de adhesión (Fig. 5). Por lo tanto, el enfoque termodinámico mostró cómo el valor total de energía libre de la adhesión de $R$. opacus sobre la superficie de magnesita fue más negativo que el sistema de calcita [14].

Tabla 5. Componentes interfacial para $R$. opacus, calcita y magnesita y el $\Delta G^{a d h}$ para los sistemas bacteria-mineral [14].

\begin{tabular}{|c|c|c|c|c|c|c|}
\hline Componente & $\begin{array}{c}\mathbf{Y}^{\mathbf{L W}} \\
\left(\mathbf{m J} / \mathbf{m}^{2}\right)\end{array}$ & $\begin{array}{c}\mathbf{Y}^{+} \\
\left(\mathbf{m J} / \mathbf{m}^{2}\right)\end{array}$ & $\begin{array}{c}\mathbf{V} \\
\left(\mathbf{m} \mathbf{J} / \mathbf{m}^{2}\right)\end{array}$ & $\begin{array}{c}\Delta \mathbf{G}^{\mathbf{L w}} \\
(\mathbf{m J})\end{array}$ & $\begin{array}{c}\Delta \mathbf{G}_{\mathrm{AB}} \\
(\mathbf{m J})\end{array}$ & $\begin{array}{c}\Delta \mathbf{G}^{\text {adh }} \\
(\mathbf{m J})\end{array}$ \\
\hline R. opacus & 0,64 & 8,12 & 28,51 & & & \\
\hline Agua & 21,8 & 25,5 & 25,5 & & & \\
\hline Calcita & 0,59 & 5,69 & 57,02 & 6,26 & $-0,77$ & $-7,03$ \\
\hline Magnesita & 3,78 & 51,14 & 9,45 & 13,24 & $-18,26$ & $-32,20$ \\
\hline
\end{tabular}

La Figura 11 muestra la energía de interacción en función de la distancia para magnesita y calcita con células de $R$. opacus aplicando las teorías de DLVO y XDLVO a pH 7, donde se informó la máxima adhesión. A partir de la misma, se notó que el mínimo secundario para la magnesita fue más profundo que la calcita, sugiriendo una interacción más fuerte entre $R$. opacus y magnesita, tal como fue mostrado en el enfoque termodinámico (Tabla 5) [14].

\subsection{Análisis FTIR}

El análisis FTIR para magnesita y calcita confirmó que el carácter de las superficies minerales cambió después de la interacción con la biomasa (ver Fig. 12).

Los espectros FTIR para magnesita y calcita, obtenidos antes de la interacción con $R$. opacus, mostraron las bandas características para los carbonatos. Las bandas de absorbancia de 1798$1812,1425-1435,876-874$ y $712 \mathrm{~cm}^{-1}$ se asignan al grupo carbonato de estiramiento asimétrico. Las bandas entre 2545 y $2514 \mathrm{~cm}^{-1}$ representan la variación de $\mathrm{Mg}^{2+}$ o $\mathrm{Ca}^{2+}$ [14].
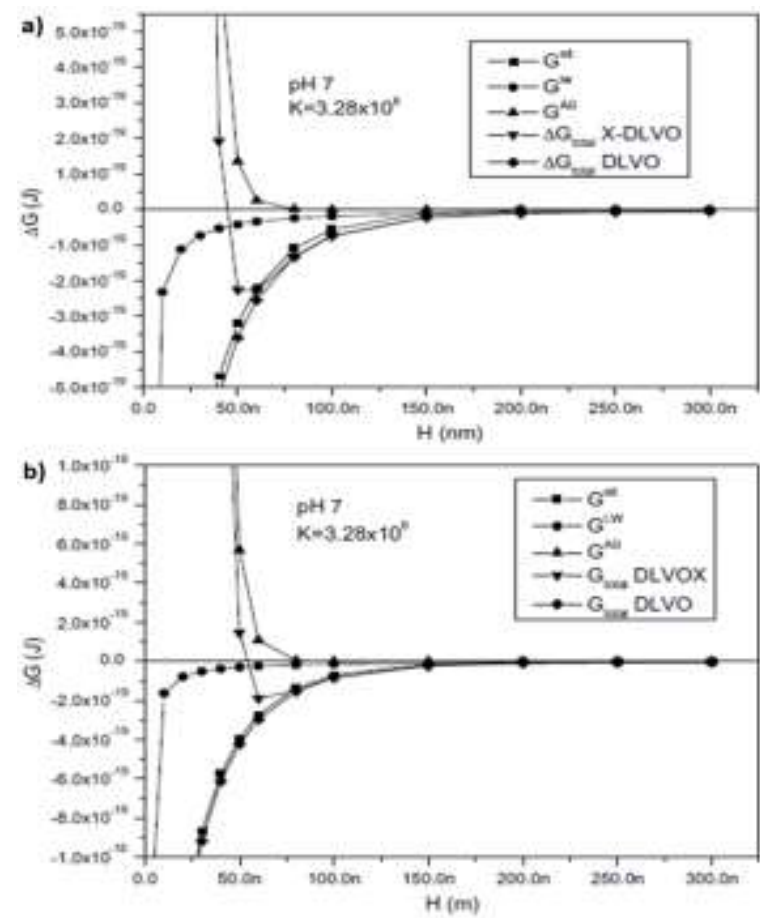

Figura 11: Teorías DLVO y X-DLVO aplicadas a la magnesita (a) y a la calcita (b) con células de $R$. opacus a $\mathrm{pH} 7$ [14].

En el caso de la magnesita, después de la interacción con $R$. opacus, los espectros exhibieron algunas modificaciones en comparación con los resultados iniciales. Las bandas de absorbancia fueron de $3400 \mathrm{~cm}^{-1}$ asignadas a grupos hidroxilo $(\mathrm{OH}$ y NH$), 2916 \mathrm{~cm}^{-1}$ asignadas a $\mathrm{CH}_{3}, 1632 \mathrm{~cm}^{-1}$ asignadas a grupos amida y $1094 \mathrm{~cm}^{-1}$ asignadas a grupos aminas. Esas modificaciones fueron 
asociadas a los grupos funcionales de la pared celular que podrían haber interactuado con la superficie de magnesita [14]. En cuanto a la calcita, sufrió modificaciones menores en comparación con los espectros de magnesita. Los resultados fueron de acuerdo con las mediciones de potencial zeta, que mostraron que el cambio del punto isoeléctrico para la magnesita fue más significativo que la calcita.
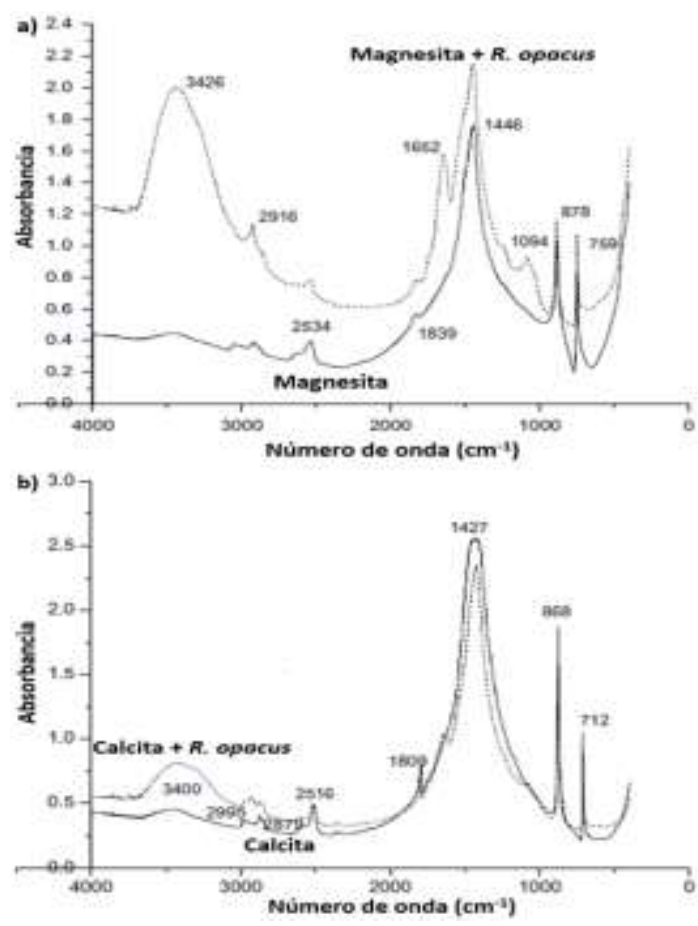

Figura 12: Espectros FTIR de magnesita (a) y calcita (b), antes y después de la interacción con $R$. opacus [10].

\subsection{Análisis MEB}

La Figura 13 muestra micrografías electrónicas de barrido de partículas de hematita y de cuarzo recogidas en la espuma después de la microflotación. Estas micrografías fueron representativas de los mejores resultados de la prueba de microflotation, a $\mathrm{pH} \mathrm{4,5}$ para hematita y $\mathrm{pH} 3,5$ para cuarzo. Aunque las células bacterianas tendieron a adherirse a ambas superficies minerales, para las partículas de hematita (Fig. 13A), la adhesión fue significativa.

La Figura 14 muestra las imágenes MEB de magnesita y calcita después de la adsorción de las células $R$. opacus. La cantidad de células de $R$. opacus adsorbidas en la superficie de magnesita es mayor que en la calcita [10]. Esto estuvo de acuerdo con los resultados de adhesión, donde se destaca la afinidad de $R$. opacus por la magnesita en comparación con la calcita.
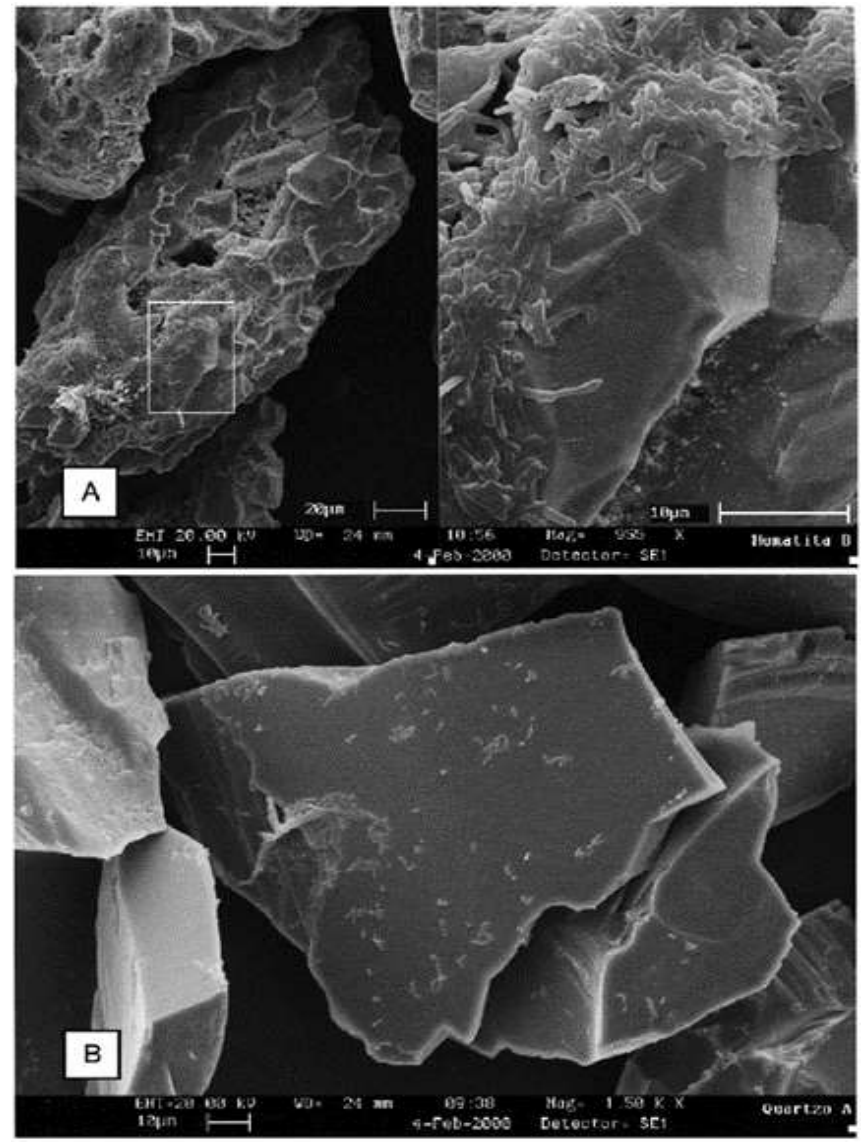

Figura 13: Fotomicrografía electrónica de barrido de partículas de hematita (A) y de cuarzo (B) flotado con células de $R$. opacus, en test de microflotation [6].

\section{Conclusiones}

Los resultados de la flotación de hematita evidenciaron el potencial uso de las células de $R$. opacus como colector a pH 4. La teoría DLVO mostró que además de las interacciones electrostáticas, hay otros mecanismos que contribuyen en los fenómenos de adhesión hematita- $R$ opacus. Sugiere un mecanismo indirecto debido a las sustancias poliméricas extracelulares (EPS) que forman fuertes enlaces químicos entre las superficies minerales y bacterianas [23].

La superficie de la magnesita sufrió mayor alteración que la calcita debido a la interacción celular, siendo el cambio de su PIE más significativo. 

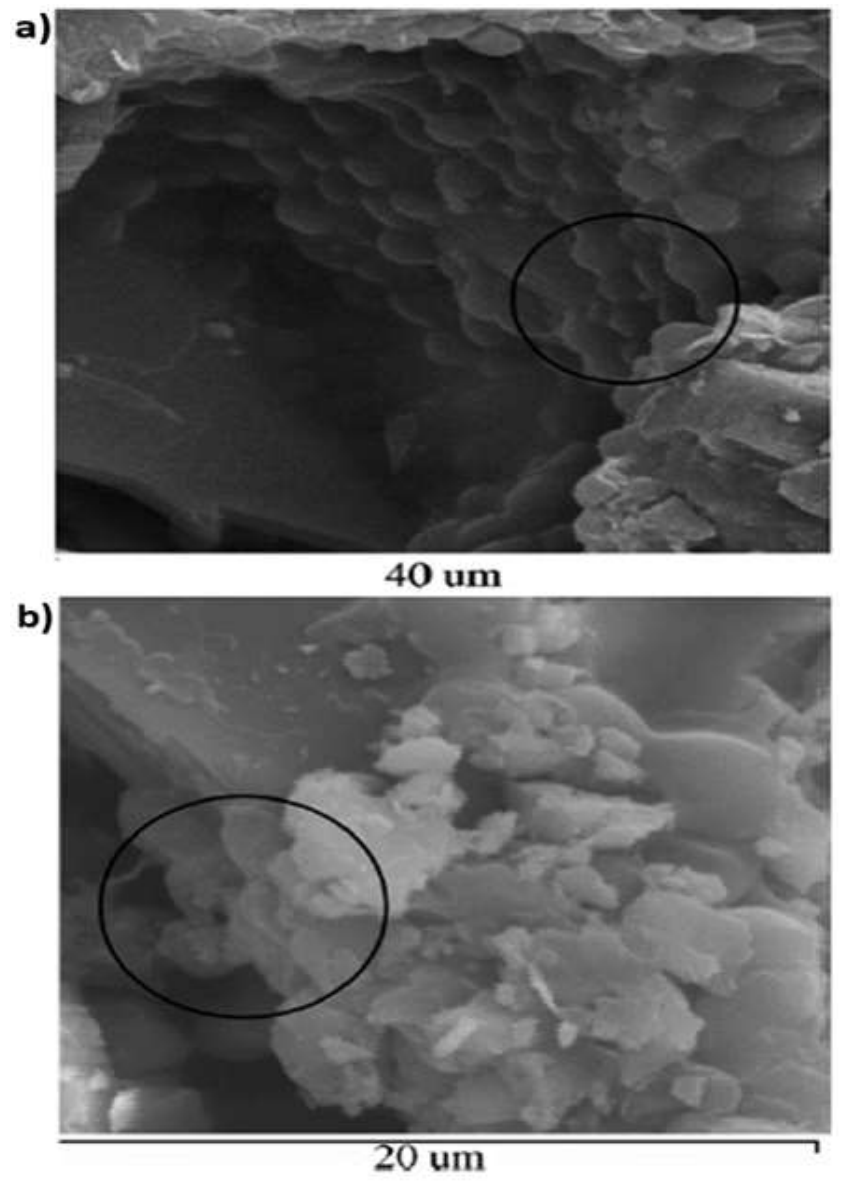

Figura 14: Fotomicrografía electrónica de barrido de partículas de magnesita (a) y de calcita (b) con células de $R$. opacus adsorbidas sobre sus superficies a $\mathrm{pH} 7$ [10].

Estos estudios sugieren la formación compleja entre metabolitos y especies de superficie como mecanismo de adsorción, indicando que las interacciones con la superficie mineral dependen en gran medida de los valores de $\mathrm{pH}$. El enfoque termodinámico predijo la mayor afinidad de $R$. opacus con magnesita que con calcita porque el primero es más energéticamente favorable. El mínimo secundario, en el análisis DLVO para la magnesita es más profundo que la calcita, lo que sugiere una interacción más fuerte entre R. opacus y magnesita, concordando con el enfoque termodinámico. Las pruebas de flotabilidad respaldaron estos resultados.

La evaluación del potencial zeta de la apatita y el cuarzo antes y después de la interacción con $R$. opacus mostró una alteración significativa en la superficie de la apatita. La selectividad de $R$. opacus se evidencia por las pruebas de flotación en las que la biomasa tiene más afinidad por la apatita que el cuarzo. Las imágenes electrónicas de barrido confirmaron esta afinidad al mostrar una cantidad significativa de células bacterianas sobre la superficie de apatita.

La bacteria $R$. opacus tiene potencial como bioreactivo, que podría disminuir el impacto ambiental y ofrecer alternativas más adecuadas para el tratamiento de depósitos minerales no económicos de baja ley. Además, se requiere más investigación para saltar a la aplicabilidad industrial. Como visión de futuro, la producción a bajo costo de un bioreactivo no tóxico, biodegradable, estable y altamente selectivo va a liderar una revolución en la industria de la flotación mineral, haciendo posible el desarrollo de un proceso sostenible con un daño mínimo al medio ambiente, característico de una química verde.

\section{Agradecimientos}

Los autores agradecen a CAPES, CNPq, PUC-Rio y a la UCV por el apoyo brindado.

\section{Referencias}

[1] P. K. Sharma, Ph.D. thesis, Luleå tekniska universitet, 2001.

[2] M. Hermansson, Colloids and Surfaces B: Biointerfaces 14 (1999) 105.

[3] K. A. Natarajan and A. Das, International Journal of Mineral Processing 72 (2003) 189.

[4] S. Pavlovic and P. R. G. Brandao, Minerals Engineering 16 (2003) 1117.

[5] S. Subramanian, D. Santhiya, and K. A. Natarajan, International Journal of Mineral Processing 72 (2003) 175.

[6] L. M. S. de Mesquita, F. F. Lins, and M. L. Torem, International Journal of Mineral Processing 71 (2003) 31.

[7] J. Lyklema, in Adsorption from Solution at the Solid/Liquid Interface, edited by G. D. Parfitt and C. H. Rochester (Academic Press, London, 1983), p. 416.

[8] N. Deo and K. A. Natarajan, Minerals Engineering 10 (1997) 1339.

[9] N. Deo and K. A. Natarajan, Int. J. Miner. Process 55 (1998) 41.

[10] A. E. C. Botero, M. L. Torem, and L. M. Souza de Mesquita, Minerals Engineering 20 (2007) 1026.

[11] A. T. Poortinga et al., Surface Science Reports 47 (2002) 1.

[12] O. S. Pokrovsky, J. Schott, and F. Thomas, Geochimica et Cosmochimica Acta 63 (1999) 863. 
[13] N. Vdović and J. Bišćan, Colloids and Surfaces A: Physicochemical and Engineering Aspects 137 (1998) 7.

[14] A. E. C. Botero, M. L. Torem, and L. M. S. de Mesquita, Minerals Engineering 21 (2008) 83.

[15] A. G. Merma et al., Minerals Engineering 48 (2013) 61.

[16] A. Vilinska and K. H. Rao, Transactions of Nonferrous Metals Society of China (English Edition) 18 (2008) 1403.

[17] J. Dubel et al., Minerals Engineering 5 (1992) 547.

[18] A. M. Raichur et al., Colloids and Surfaces B: Biointerfaces 8 (1996) 13.

[19] M. Farahat et al., Minerals Engineering 21 (2008) 389.

[20] N. Deo, K. A. Natarajan, and P. Somasundaran, International Journal of Mineral Processing 62 (2001) 27.
[21] M. N. Chandraprabha and K. A. Natarajan, Hydrometallurgy 83 (2006) 146.

[22] M. C. M. van Loosdrecht et al., Microbial Ecology 17 (1989) 1.

[23] P. K. Sharma and K. H. Rao, Mining, Metallurgy \& Exploration 16 (1999) 35.

[24] R. M. Pashley and M. E. Karaman, Applied Colloid and Surface Chemistry (John Wiley \& Sons, Ltd, Chichester, UK, 2004).

[25] I. A. H. Schneider, M. Misra, and R. W. Smith, Developments in Chemical Engineering and Mineral Processing 2 (2008) 248.

[26] R. R. Hacha, M. L. Torem, A. Gutiérrez Merma, and V. F. da Silva Coelho, Miner. Eng. 126, (2018) 105.

E-mail: caralcaso@gmail.com, jhona sp@hotmail.com 